\title{
Short-term Administration of Conjugated Linoleic Acid Reduces Liver Triglyceride Concentration and Phosphatidate Phosphohydrolase Activity in OLETF Rats
}

\author{
Shaikh Mizanoor Rahman ${ }^{\dagger}$, M. Nazmul Huda, M. Nasir Uddin and Sharif Akhteruzzaman* \\ Department of Biochemistry and Molecular Biology, University of Dhaka, Dhaka-1000, Bangladesh \\ 'Department of Applied Biological Sciences, Saga University, Saga 840-8502, Japan
}

Received 30 April 2002, Accepted 10 August 2002

\begin{abstract}
The present study explored the short-term effects of dietary conjugated-linoleic acid (CLA) on liver lipid metabolism in starved/refed Otsuka Long Evans Tokushima Fatty (OLETF) rats. Male OLETF rats (12 weeks old) were starved for 24 hours, then refed for 48 hours with either a CLA diet [7.5\% CLA and $7.5 \%$ Safflower oil (SAF)] or a SAF control diet (15\% SAF). The results demonstrated a $30 \%$ reduction of hepatic triglyceride (TG) concentration in the CLA group when compared to the control group. Liver cholesterol concentration was also $26 \%$ lower in the CLA fed rats. The activity of mitochondrial carnitine palmitoyltransferase, the rate-limiting enzyme of fatty acid oxidation, was moderately elevated by 1.2 -fold in the livers of the CLA group when compared to the control. In contrast, phosphatidate phosphohydrolase, the ratelimiting enzyme for TG synthesis, was found to be $\mathbf{2 0 \%}$ lower in the livers of the CLA-fed rats. Therefore, dietary CLA evidently lowers liver lipid concentrations through a reduced TG synthesis and enhanced fatty acid oxidation in starved/refed OLETF rats.
\end{abstract}

Keywords: Carnitine palmitoyltransferase, Conjugatedlinoleic acid, Phosphatidate phosphohydrolase

\section{Introduction}

Conjugated linoleic acid (CLA) refers to a group of positional (9/11 or 10/12 double bonds) and geometric (various cis/trans combinations) isomers that are derived from linoleic acid (cis9, cis12-octadecadienoic acid). They are found in edible foods, such as ruminants meats, pasteurized dairy products,

*To whom correspondence should be addressed. Tel: 880-2-9661920/6113; Fax: 880-2-8615583

E-mail: sharif@cgscomm.net and processed cheeses (Ha et al., 1989; Chin et al., 1992). CLA exhibits several beneficial effects, such as a protective effect against cancer and heart disease (Ip et al., 1991; Ip et al., 1994; Lee et al., 1994), and reduced body fat mass in experimental animals (Park et al., 1997; West et al., 1997; Park et al., 1999). Furthermore, Houseknecht et al. showed that CLA is capable of improving glucose tolerance in hyperglycemic Zucker rats (Houseknecht et al., 1998).

Re-feeding after starvation leads to a significant increase in lipogenesis in the liver and white adipose tissue in experimental animals (Owens et al., 1979; Kochan et al., 1997). This physiological alteration may have some advantages for survival by directing the newly-synthesized fatty acids to form triglycerides as a high-energy source; this increases weight and lipid accumulation in the liver and adipose tissues (Nace et al., 1976; Baltzell et al., 1985). Belury et al. observed that CLA can modulate hepatic lipid composition in rats. However, it is unclear whether or not the short-term feeding of CLA influences the hepatic lipid metabolism in the starved/re-fed animal model.

In the present study, we employed Otsuka Long-Evans Tokushima Fatty (OLETF) rats, which develop obesity, noninsulin dependent diabetes mellitus with early hypertriglyceridemia, and hyperinsulinemia in adulthood (Kawano et al., 1992; Kawano et al., 1994). We, therefore, evaluated the dietary influences of CLA on hepatic lipid metabolism in this animal model.

\section{Materials and Methods}

Animals and diets Male OLETF rats were a generous gift from the Tokushima Research Institute (Otsuka Pharmaceutical Co. Ltd., Tokushima, Japan). The rats were individually housed in metal cages in a temperature-controlled $\left(24^{\circ} \mathrm{C}\right)$ room under a 12-hour light/dark cycle. All of the animals were fed chow powder ad libitum until they were given the experimental diet. At 12 weeks of age (body eight 440-450 g), the rats were divided into control and 
CLA groups. Each group contained five rats. Both of the rat groups were starved for 24 hours, then re-fed for 48 hours with one of the following diets. The CLA group was fed with powdered chow that was supplemented with $7.5 \%$ safflower oil (SAF) and 7.5\% CLA. The control group was fed with powdered chow that was supplemented with $15 \%$ SAF. CLEA, Inc. (Tokyo, Japan) provided the powdered chow. The ingredient composition was as follows: crude protein $25.4 \%$, crude fat $4.2 \%$, non-nitrogen compound $50.3 \%$, and moisture $8.9 \%$. CLA and SAF oil were obtained from Rinoru Oil Mills Co. Ltd. (Nagoya, Japan). The CLA mixture was composed of $33.2 \%$ of 9 -cis, 11 trans/9 trans, 11 cis $18: 2 ; 34.2 \%$ of 10 trans, 12 cis $-18: 2 ; 2.4 \%$ of $9 \mathrm{cis}, 11 \mathrm{cis} / 10 \mathrm{cis}, 12 \mathrm{cis}-18: 2$; and $1.8 \%$ of 9 trans. 11 trans/10 trans, 12 trans-18:2 fatty acids. At the end of the experimental period, the rats were sacrificed under diethyl ether anesthesia. Blood samples were taken from the vena cava, and the tissues were excised and kept frozen at $-80^{\circ} \mathrm{C}$ until they were analyzed.

Determination of serum lipids Serum was separated by centrifuging the blood at $3000 \mathrm{rpm}$ for $15 \mathrm{~min}$. Triglyceride, total cholesterol, HDL-cholesterol, non-esterified fatty acid (NEFA), and phospholipids in serum were measured with commercial kits that were supplied by Roche Diagnostics GmbH, Germany.

Determination of liver lipids A portion of the fresh liver from each rat was homogenized in an ice-cold $10 \mathrm{mM}$ Tris- $\mathrm{HCl}$ buffer (pH 7.4) that contained $0.25 \mathrm{M}$ sucrose and $1 \mathrm{mM}$ EDTA (buffer A). Then the homogenate was centrifuged at $20,000 \times g$ for $20 \mathrm{~min}$ at $4^{\circ} \mathrm{C}$. The supernatant of each homogenate was filtered through a nylon mesh, then centrifuged again at $105,000 \times g$ for $45 \mathrm{~min}$ at $4^{\circ} \mathrm{C}$. The resulting supernatant was collected as a cytosolic fraction. The pellet was gently homogenized with a small volume of buffer A, and used as a microsomal fraction. Protein levels were measured by the method of Lowry et al. with bovine serum albumin as the standard (Lowry et al., 1951). Hepatic lipid concentrations were measured according to established protocols (Cha et al., 1998; Ikeda et al. 1998).

Enzyme assay Phosphatidate phosphohydrolase (PAP; EC 3.13.4), malic enzyme (EC 1.1.1.40), glucose-6-phosphate dehydrogenase (G6PDH; EC 1.1.1.49), and carnitine palmitoyltransferase (CPT; EC 2.3.1.23) were measured as described previously (Cha et al., 1998; Ikeda et al., 1998; Martin et al., 2000).

Stastistical analyses All of the values are expressed as means \pm SE. Data were analyzed by a one-way analysis of variance (ANOVA), followed by an inspection of all of the differences by a Students $t$-test. The differences were considered significant at $p<0.05$.

\section{Results and Discussion}

The present study investigated the effect of the short-term feeding of the dietary CLA on hepatic lipid metabolism in starved/refed OLETF rats. The results demonstrated a $31 \%$ reduction of hepatic triglyceride content in the CLA-fed
Table 1. Effect of CLA on hepatic lipid concentration in starved/ re-fed OLETF rats

\begin{tabular}{ccc}
\hline & Control (mg/g liver) & CLA (mg/g liver) \\
\hline Triglycerides & $49.0 \pm 2.8$ & $34.3 \pm 3.1^{*}$ \\
Total cholesterol & $4.05 \pm 0.25$ & $3.01 \pm 0.26^{*}$ \\
Phospholoipid & $23.1 \pm 0.7$ & $23.8 \pm 0.6$ \\
\hline
\end{tabular}

Data are means $\pm \mathrm{SE}$ of five rats. Rats were starved for $24 \mathrm{~h}$ and then re-fed for $48 \mathrm{~h}$ with one of the following diets: CLA group was fed powdered chow supplemented with $7.5 \%$ safflower oil and $7.5 \%$ CLA, and the control group was fed powdered chow supplemented with $15 \%$ safflower oil. $*(p<0.05$ vs. control).

Table 2. Effect of CLA on enzyme activities in liver of starved/ re-fed OLETF rats

\begin{tabular}{ccc}
\hline & \multicolumn{2}{c}{$\begin{array}{c}\text { Enzyme activity } \\
\text { expressed as nmol/min/mg protein }\end{array}$} \\
\cline { 2 - 3 } & Control & CLA \\
\hline CPT & $11.1 \pm 1.6$ & $14.8 \pm 2.1$ \\
PAP & $22.2 \pm 0.5$ & $17.8 \pm 0.5^{* * *}$ \\
Malic enzyme & $53.5 \pm 2.0$ & $59.1 \pm 4.4$ \\
G6PDH & $47.0 \pm 2.3$ & $47.3 \pm 5.0$ \\
\hline
\end{tabular}

Data are mean \pm SE of five rats. Rats were starved for $24 \mathrm{~h}$ and then re-fed for $48 \mathrm{~h}$ with one of the following diets: CLA group was fed powdered chow supplemented with $7.5 \%$ safflower oil and $7.5 \%$ CLA, and the control group was fed powdered chow supplemented with $15 \%$ safflower oil. PAP activity was measured using liver microsomal fraction, malic enzyme and G6PDH were measured in liver cytosolic fraction, while CPT activity was measured in liver homogenate fraction. CPT; Carnitine palmitoyl transferase, PAP; Phosphatidate phosphohydrolase, G6PDH; Glucose-6-phosphate dehydrogenase. $* * *(p<0.0001$ vs. control $)$

OLETF rats when compared to the control rats (Table 1). Similarly, the liver cholesterol concentration was $26 \%$ lower in the CLA fed rats.

The investigation then researched what leads to the reduction of hepatic lipid after the CLA administration. We measured the activities of two key enzymes; CPT for fatty acid oxidation and PAP for TG synthesis in liver. The present study found that there was a tendency to increase the CPT activity in the livers of the CLA-fed rats when compared to the control rats (Table 2). Short-term CLA feeding also enhanced the CPT activity in the brown and white adipose tissues of CLA-fed OLETF rats. Regarding the CPT activity increase in the CLA-fed OLETF rats, it may be assumed that CLA might alter the cellular expression of CPT mRNA. Another possibility is the involvement of peroxisome proliferator-activated receptors (PPARs). It was reported that CLA has structural and physiological characteristics that are similar to PPARs (Moya-Camarena et al., 1999). It is known that liver fatty acid catabolism is regulated by PPAR-alpha 


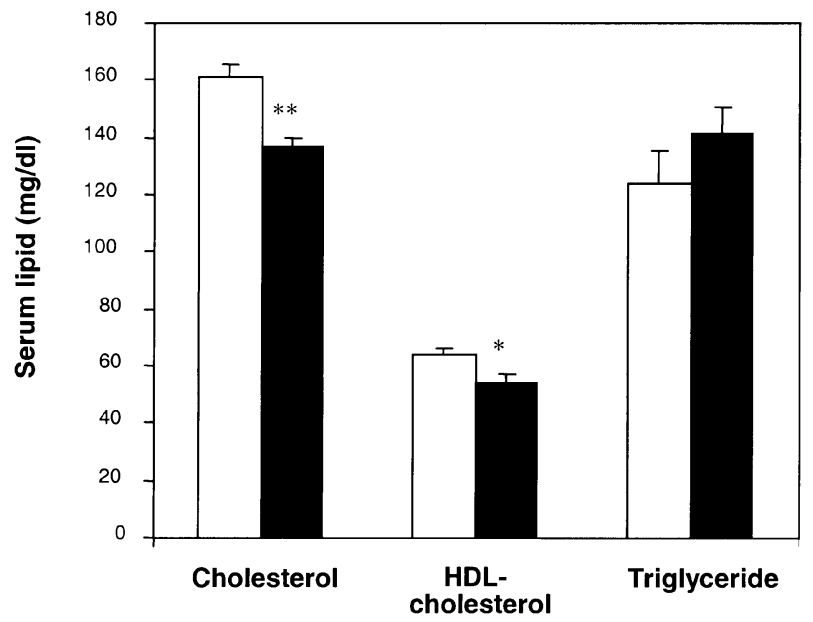

Fig. 1. Effect of CLA on serum lipid concentrations in starved/ refed OLETF rats. Data are means \pm SE of five rats. Rats were starved for $24 \mathrm{~h}$ and then re-fed for $48 \mathrm{~h}$ with one of the following diets: CLA group was fed powdered chow supplemented with $7.5 \%$ safflower oil and 7.5\% CLA ( $\mathbf{\square}$ ), and the control group $(\square)$ was powdered chow supplemented with $15 \%$ safflower oil. ( $* p<0.05$ vs control; $* * p<0.001)$.

(Pineda et al., 1999). Hence, it is likely that CLA, by upregulating PPAR-alpha, may enhance the $\beta$-oxidation of fatty acid in liver.

Next, the CLA effect on hepatic TG synthetic enzyme, PAP, was investigated. It was reported that the $\mathrm{Mg}^{2+}$-dependent PAP activity is the rate-limiting enzyme for the TG synthesis (Gomez-Munoz et al., 1992; Jamal et al., 1992). The present study demonstrated a $20 \%$ reduction of hepatic microsomal PAP activity in CLA-fed rats $(p<0.001)$ when compared to rats that were fed the control diet (Table 2). This suggests a CLA dependent reduction in liver TG synthesis. Availability of fatty acid is an important factor for TG synthesis (Halminski et al., 1991), because the partition of fatty acids that are supplied from endogenous and exogenous origins into the TG molecule is reciprocally-related to the oxidation process. The decrease in PAP activity, and an increased tendency of CPT activity that is caused by dietary CLA, implies that fatty acids are degraded through $\beta$-oxidation rather than utilized for TG synthesis.

The present study also measured the activities of lipogenic enzymes, such as malic enzyme and glucose-6-phosphate dehydrogenase (Table 2). No change in enzyme activities was observed, unlike earlier studies (Nace et al., 1976; Kochan et al., 1997). This could be due to the experimental animal conditions that are employed herein, and those that were reported by others.

In addition to the alteration of hepatic lipids and enzymes that are involved in TG catabolism, dietary CLA reduced the serum total and HDL-cholesterol concentrations (Fig. 1). Our result on the CLA-induced reduction of serum cholesterol concentration confirms earlier reports, where the dietary
CLA-induced reduction of serum cholesterol levels in hamsters and rabbits were reported (Lee et al., 1994; Gavino et al., 2000). Moreover, our result indicates that the short-term administration of CLA can reduce the serum cholesterol concentration in obese diabetic OLETF rats.

In this study, we found no changes in the serum TG concentration between the CLA and control groups (Fig. 1), though hepatic TG and PAP activities were reduced. One possibility might be the impaired removal of VLDL-TG after the CLA feeding. There are numerous studies that show the CLA effects on normal rats (Lee et al., 1994; Belury et al., 1997; Park et al., 1997). However, most of these studies have shown the long-term feeding effects (1-4 weeks of feeding). Our data (so far the first of this type) shows that CLA reduces liver TG, as well as blood cholesterol, after 48 hours of feeding. In addition, none of the previous studies showed the lipid-lowering effects of CLA on the liver and blood. From this point-of-view, it is reasonable to say that the effect is unique in this type of rat model. However, no study on the short term CLA effect on normal rats has been undertaken. Therefore, further study will be necessary to clarify this point.

In conclusion, a 48-hr supplementation of CLA to the diet caused a significant reduction of hepatic TG and cholesterol concentration in starved/re-fed OLETF rats. This reduction may be attributed to both the enhanced $\beta$-oxidation of fatty acids and the reduced triglyceride synthesis in the livers of starved/re-fed OLETF rats.

\section{References}

Baltzell, J. K. and Berdanier, C. D. (1985) Effect on the interaction of dietary carbohydrate and fat on the responses of rats to starvation/refeeding. J. Nutr. 115, 104-110.

Belury, M. A. and Kempa-Steczko, A. (1997) Conjugated linoleic acid modulates hepatic lipid composition in mice. Lipids 32, 199-204.

Cha, J. Y., Yamagata, Y., Yamamoto, K., Oogani, K. and Yanagita, T. (1998) Association between hepatic triacylglycerol accumulation induced by administering orotic acid and enhanced phosphatide phosphorylase activity in rats. Biosci. Biotech. Biochem. 62, 508-513.

Chin, S. F., Liu, W., Storkson, J. M., Ha, Y. L. and Pariza, M. W. (1992) Dietary sources of conjugated dienoic isomers of linoleic acid, a newly recognized class of anticarcinogens. $J$. Food Compos. Anal. 5, 185-197.

Fisher, R. A. (1970) Statistical methods for research workers. Vol. 14, pp. 140-142. Oliver and Boyd, Edinburgh, U.K.

Gavino, V. C., Gavino, G., Leblanc, M. J. and Tuchweber, B. (2000) An isomeric mixture of conjugated linoleic acids but not pure cis-9, trans-11-octadecadienoic acid affects body weight gain and plasma lipids in hamsters. J. Nutr. 130, 27-29.

Gomez-Munoz, A., Hatch, G. M., Martin, A., Jamal, Z., Vance, D. E. and Brindley, D. N. (1992) Effect of Okadaic acid on the activities of two distinct phosphatidate phosphohydrolase in rat hepatocytes. FEBS Lett. 301, 103-106.

Ha, Y. L., Grimm, N. K. and Pariza, M. W. (1989) Newlyrecognized anticarcinogenic fatty acids: identification and 
quantification in natural and processed cheeses. J. Agri. Food Chem. 37, 75-81.

Halminski, M. A., Marsh, J. B. and Harrison, E. H. (1991) Differential effects of fish oil, safflower oil and palm oil on fatty acid oxidation and glycerlipid synthesis in rat liver. $J$. Nutr. 121, 1554-1561.

Houseknecht, K. L., Heuvel, J. P. V., Moya-Camarena, S. Y., Portocarrero, C. P., Peck, L. W., Nickel, K. P. and Belury, M. A. (1998) Dietary conjugated linoleic acid normalizes impaired glucose tolerance in the Zucker diabetic fa/fa rat. Biochem. Biophys. Res. Commun. 244, 678-682.

Ikeda, I., Cha, J. Y., Yanagita, T., Nakatani, N., Oogami, K., Imaizumi, K. and Yazawa, K. (1998) Effects of dietary alphalinoleic, eicosapentaenoic and decosahexaenoic acids on hepatic lipogenesis and beta-oxidation in rats. Biosci. Biotech. Biochem. 62, 675-680.

Ip, C., Singh, M., Thompson, H. J. and Scimeca, J. A. (1991) Conjugated linoleic acid suppresses mammary carcinogenesis and proliferative activity of the mammary gland in rat. Cancer Res. 54, 1212-1215.

Ip, C., Scimeca, J. A. and Thompson, H. J. (1994) Conjugated linoleic acid, a powerful anticarcinogen from animal fat sources. Cancer 74, 1050-1054.

Jamal, Z., Martin, A., Gomez-Munoz, A., Hales, P., Chang, P., Russell, J. C. and Brindley, D. N. (1992) Phosphatidate phosphohydrolase in the liver, heart and adipose tissue of the JCR: LA Corpulant rat and the lean genotypes: implications for glycerolipid synthesis and signal transduction. Int. J. Obesity 16, 789-799.

Kawano, K., Hirashima, T., Mori, S., Saitoh, Y., Kuroshima, M. and Natori, T. (1992) Spontaneous long-term hyperglycemic rat with diabetic complications: Otsuka Long-Evans Tokushima Fatty (OLETF) strain. Diabetes 41, 1422-1428.

Kawano, K., Hirashima, T., Mori, S. and Natori, T. (1994) Otsuka Long-Evans Tokushima Fatty (OLETF) rat: a new NIDDM rat strain. Diabetes Res. Clin. Practice 24, S317-S320.

Kochan, Z., Karbowska, J. and Swierczynski, J. (1997) Unusual increase of lipogenesis in rat whit adipose tissue after multiple cycles of starvation and refeeding. Metabolism 46, 10-17.

Lee, K. N., Kritchevsky, D. and Pariza, M. W. (1994) Conjugated linoleic acid and atherosclerosis in rabbits. Atherosclerosis 108, 19-25.

Lowry, O. H., Rosenbrough, N. J., Farr, A. L. and Randall, R. J. (1951) Protein measurement with the Folin phenol reagent. $J$. Biol. Chem. 193, 265-275.

Matin, J. C., Gregire, S., Siess, M. H., Genty, M., Chardigny, J. M., Berdeaux, O., Juaneda, P. and Sebedio, J. L. (2000) Effects of conjugated linoleic acid isomers towards lipid metabolizing enzymes in male wister rats. Lipids 35, 91-98.

Moya-Camarena, S. Y., Heuvel, J. P. V. and Belury, M. A. (1999) Conjugated linoleic acid activates peroxisome proliferatorsactivated receptor alpha and beta subtypes but does not induce hepatic peroxisome proliferation in Sprague-dawley rate. Biochim. Biophys. Acta 1436, 331-342.

Nace, C. S. and Szepesi, B. (1976) Dietary fatty acids on the control of glucose-6-phosphate dehydrogenase and malic enzyme in the starvedrefed rats. J. Nutr. 106, 285-291.

Owens, J. L., Thompson, D., Shah, N. and Digirolamo, M. (1979) Effects of fasting and refeeding in the rat on adipocyte metabolic functions and response to insulin. J. Nutr. 109, 15841591.

Park, Y., Albright, K. J., Liu, W., Storkson, J. M., Cook, M. E. and Pariza, M. W. (1997) Effect of conjugated linoleic acid on body composition in mice. Lipids 32, 853-858.

Park, Y., Albright, K. J., Storkson, J. M., Cook, M. E. and Pariza, M. W. (1999) Changes in body composition in mice during feeding and withdrawal of conjugated linoleic acid. Lipids 34, 243-248.

Pineda Torra, I., Gervois, P. and Staels, B. (1999) Peroxisome proliferator-activated receptor alpha in metabolic disease, inflammation, atherscerosis and aging. Curr. Opin. Lipidol. 10, 151-159.

West, D. B., DeLany, J. P., Camet, P. M., Blohm, F., Truett, A. A. and Scimeca, J. (1998) Effects of conjugated linoleic acid on body fat and energy metabolism in the mouse. Am. J. Physiol. 275, R667-R672. 